\title{
New lightweight geomaterials: Biocemented sand mixed with expanded polystyrene beads
}

\author{
XIAO Yang ${ }^{1,2,3 *}$, HE Xiang ${ }^{2,3}$ \& LIU HanLong ${ }^{2,3 *}$ \\ ${ }^{1}$ State Key Laboratory of Coal Mine Disaster Dynamics and Control, Chongqing University, Chongqing 400030, China; \\ ${ }^{2}$ Key Laboratory of New Technology for Construction of Cities in Mountain Area, Chongqing University, Chongqing 400045, China; \\ ${ }^{3}$ College of Civil Engineering, Chongqing University, Chongqing 400045, China
}

Received November 29, 2016; accepted March 17, 2017; published online May 22, 2017

Lightweight geomaterial (LWGM) possesses such merit characteristics as low unit weight, environmental protection (recycling these materials instead of stockpiling them), buffering mechanical property and thermal insulation [1]. LWGM, an attractive substitute for earth fills, can be applied in special geotechnical engineering, such as flexible pipeline, widened embankment, bridge abutments, soft ground improvement, retaining wall, harbor construction, and railway embankment. Generally, LWGM could be categorized into three categories. The first one is pure lightweight materials such as tyre-chip assemblages and expanded polystyrene (EPS) block. The second one is soils mixed with pure lightweight geomaterials (e.g., EPS-soil mixtures or rubber chip-sand mixtures). The third one is the lightweight materials reinforced by cement-like materials, e.g., soil-EPS bead mixtures improved with Portland cement [2,3]. Previous studies show that the EPS content greatly affects the shear strength and unit weight of EPS-sand mixtures. The EPS-weight content of $0.5 \%$ suggested by Deng and Xiao [4] could achieve reasonable shear strength as well as a $26 \%$ reduction in unit weight. It was also recognized that the strength and deformation properties of LWGM were significantly improved due to the application of cement-like materials. An appropriate addition of Portland cement ranges from $0.04 \mathrm{~g} / \mathrm{cm}^{3}$ to $0.08 \mathrm{~g} / \mathrm{cm}^{3}$ [5]. However, the application of Portland cement to the LWGM is not environment-friendly, since vast energy in the production was consumed along with a great amount of carbon emission. In addition, the soil moisture content needs to be carefully considered during the cement hydration.

*Corresponding authors (email: hhuxyanson@163.com; hliuhhu@163.com)
It was recently reported that the microorganism played a signficant role in naturally forming carbonate minerals. Consequently, this effective way using microorganism was proposed to bond granular soils, to mend fracture of rock or concrete, to clog porous materials, et al. This cement-like and environment-friendly material is called biocement [6,7]. Additionally, the biocement process for engeering implementation was more natual and convenient than that of the Portland cement.

A new lightweight geomaterial (biocemented EPS-sand mixture) is produced using conventional hydraulic percolation in this work. This new material assimilates both advantages of the LWGM and biocement materials. Figure 1 illustrates preparations of the bacteria solution. Figure 1(a) shows that a stock culture in a petri dish was firstly used as the first generation of bacteria, which were inoculated to the $\mathrm{NH}_{4}$-Yeast liquid media in flasks, as shown in Figure 1(b). The activities of bacteria were measured in Figure 1(c). Then, the bacteria were cultivated in an enrichment way in Figure 1(d). Finally, bacteria were centrifuged at the rate of $4000 \mathrm{r} / \mathrm{min}$ for $25 \mathrm{~min}$ shown in Figure 1(e), and afterwards stored in the $\mathrm{NaCl}$ solution of $4{ }^{\circ} \mathrm{C}$ in refrigerator (Figure 1(f)).

Figure 2(a) shows particle size distributions of silica sand and EPS beads used in the current tests. The grain shape of the silica sand is agular [8,9] while the EPS-bead shape is perfectly rounded, as can be seen from Figure 2(b). The bacteria solution in the optimum moisture content of $8.9 \%$ was added to the EPS-sand mixture in Figure 2(c). The final observation sand-EPS mixture was illustrated in Figure 2(d). Unlike the reinforcement process using Portland cement for 


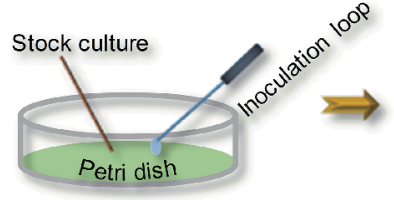

(a)

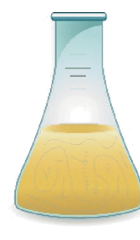

Cultivation

(d)

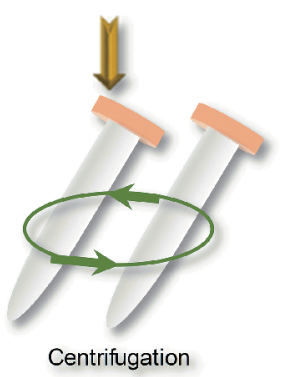

(e)

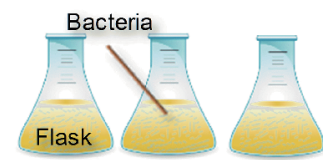

Inoculation

(b)

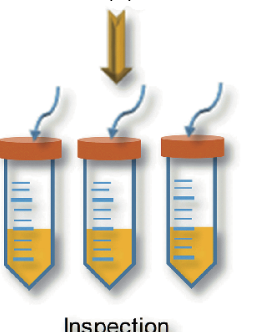

(c)

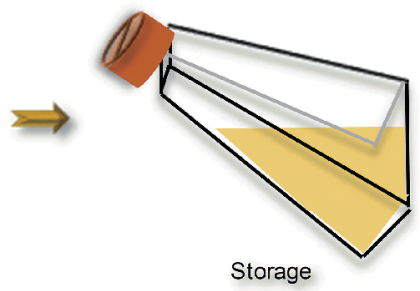

(f)
Figure 1 Diagrams for preparing bacteria solution. (a) Stock culture in petri dish; (b) inoculation of liquid media from stock culture; (c) inspection for choosing a optium culture; (d) enlarging cultivation; (e) harvest and centrifugation in $4{ }^{\circ} \mathrm{C}$; (f) storage in the $\mathrm{NaCl}$ solution of $4{ }^{\circ} \mathrm{C}$.
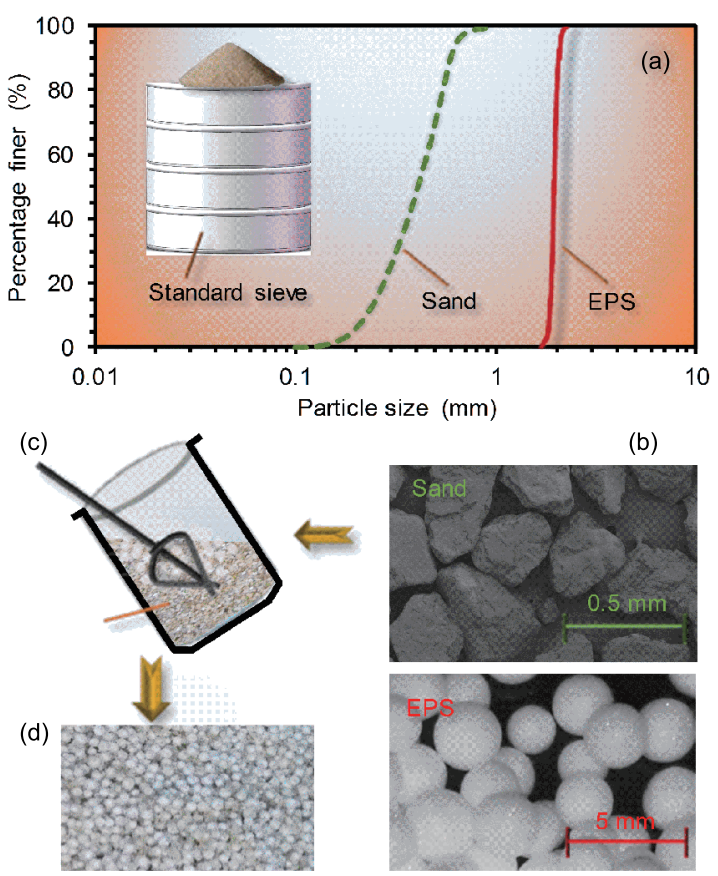

Figure 2 Preparetion of sand-EPS sample. (a) Sieving test for determinations of particle size distribution of sands and EPS; (b) micrograph of sand grains and photograph of EPS beads; (c) blending sands and EPS beads; (d) observation of sand-EPS mixture. lightweight geomaterials, a hydraulic percolation was used in a natual way for the sand-EPS mixture. A sand-EPS mixture was devided into eight equal parts, which were carefully dropped into a Polyvinyl chloride (PVC) pipe. Filters at the ends of the PVC pipe and gravels at the bottom of the pipe were used for avoiding the erosion of sand. The bacteria and nutrients solutions in Figure 3(a) were sequentially injected to the sand-EPS sample through a peristaltic pump. A biocemented sand-EPS sample was demolded, as can be seen in Figure 3(b). The biocement could fill the void among sand and EPS beads in comparisons of Figure 2(d) and Figure 3(b). The sample density of the biocemented sand-EPS mixture is $0.99 \mathrm{~g} / \mathrm{cm}^{3}$, which is much lower than the sample density $\left(1.8 \mathrm{~g} / \mathrm{cm}^{3}\right)$ of clean sands. Finally, the sample was compressed through the unconfined compression-test apparatus for evaluating the unconfined strength (UCS) (Figure 3(c)).

The UCS of the biocemented sand-EPS sample was larger than $300 \mathrm{kPa}$ with a three-day treatment. It could be observed from Figure 4 that the UCS of biocemented LWGM was slightly higher than that of the lightweight geomaterials reinforced by $9 \%$ Portland cement [10] with a fourteen-day

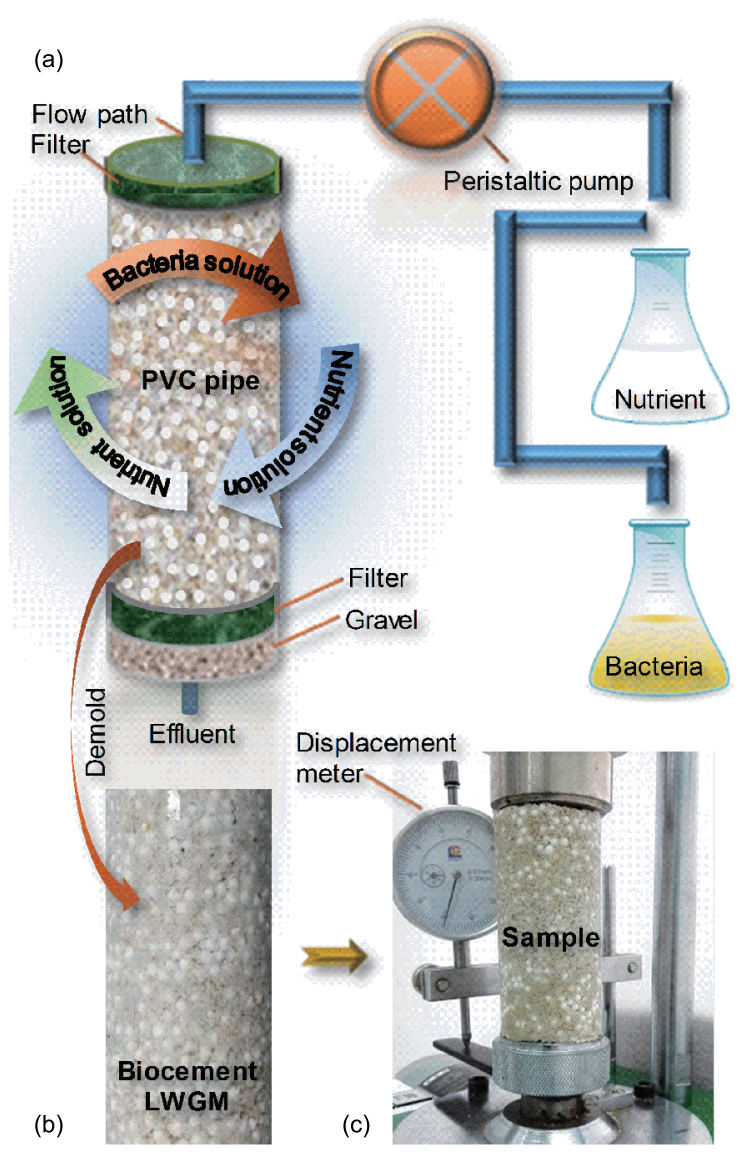

Figure 3 Biocemented lightweight geomaterials specimen. (a) Percolation process with bacteria and nutrient solution in a cylindrical PVC pipe; (b) biocemented sand-EPS sample; (c) UCS strength test for biocemented sandEPS sample. 


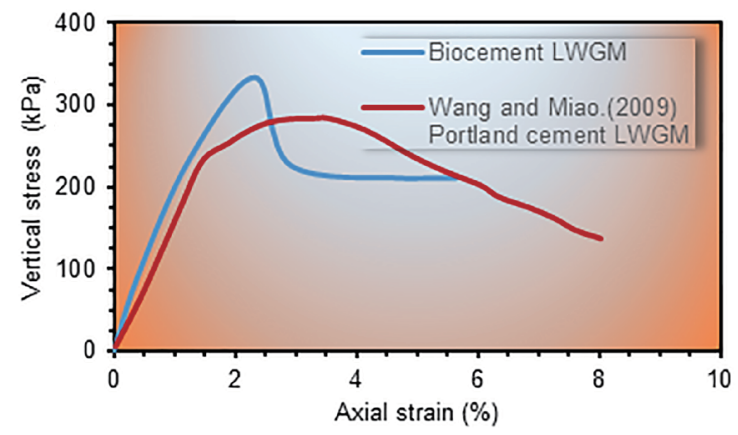

Figure 4 Comparisons of UCS strengths of biocemented LWGM and Portland cemented LWGM.

curing, where the EPS-bead content are approximately the same. However, the curing time of Portland cement is much longer than that of the biocemt. Consequently, the biocemented lightweight geomaterial could be attractive in geotechnical engineering. It should be noted that particle breakage $[11,12]$ during compressioin was not considered in the tests. More tests on strength and deformation influenced by the EPS content and biocement content would be introduced in the future work.

1 Wen Z, Sheng Y, Ma W, et al. In situ experimental study on thermal protection effects of the insulation method on warm permafrost. Cold Regions Sci Tech, 2008, 53: 369-381
2 Liu H, Deng A, Chu J. Effect of different mixing ratios of polystyrene pre-puff beads and cement on the mechanical behaviour of lightweight fill. Geotext Geomembranes, 2006, 24: 331-338

3 Edinçliler A, Özer A T. Effects of EPS bead inclusions on stress-strain behaviour of sand. Geosynth Int, 2014, 21: 89-102

4 Deng A, Xiao Y. Measuring and modeling proportion-dependent stress-strain behavior of EPS-sand mixture. Int J Geomech, 2010, 10: $214-222$

5 Onishi K, Tsukamoto Y, Saito R, et al. Strength and small-strain modulus of lightweight geomaterials: Cement-stabilised sand mixed with compressible expanded polystyrene beads. Geosynth Int, 2010, 17: 380-388

6 Chu J, Ivanov V, Naeimi M, et al. Optimization of calcium-based bioclogging and biocementation of sand. Acta Geotech, 2014, 9: $277-285$

7 Chu J, Ivanov V, Stabnikov V, et al. Microbial method for construction of an aquaculture pond in sand. Géotechnique, 2013, 63: 871-875

8 Xiao Y, Sun YF, Liu HL, et al. Model predictions for behaviors of sand-nonplastic-fines mixtures using equivalent-skeleton void-ratio state index. Sci China Tech Sci, 2017, doi: 10.1007/s11431-0169024-9

9 Xiao Y, Sun Y, Yin F, et al. Constitutive modeling for transparent granular soils. Int J Geomech, 2017, 17: 04016150

10 Wang F, Miao L. A proposed lightweight fill for embankments using cement-treated Yangzi River sand and expanded polystyrene (EPS) beads. Bull Eng Geol Environ, 2009, 68: 517-524

11 Xiao Y, Liu H. Elastoplastic constitutive model for rockfill materials considering particle breakage. Int J Geomech, 2017, 17: 04016041

12 Xiao Y, Liu H, Desai C S, et al. Effect of intermediate principal-stress ratio on particle breakage of rockfill material. J Geotech Geoenviron Eng, 2016, 142: 06015017 